\title{
Physiological Factors Affecting Response of Mature 'Valencia' Orange Fruit to CMN-Pyrazole. II. Endogenous Concentrations of Indole-3-Acetic Acid, Abscisic Acid, and Ethylene
}

\author{
Rongcai Yuan, Ulrich Hartmond, and Walter J. Kender ${ }^{1}$ \\ University of Florida, Institute for Food and Agricultural Sciences, Citrus Research and Education \\ Center, 700 Experiment Station Road, Lake Alfred FL 33850-2299
}

\begin{abstract}
AdDitional INDEX words. Citrus sinensis, fruit detachment force, regreening, abscission zone, abscission chemical
ABstract. Endogenous concentrations of IAA and ABA in the peel, pulp, seed, and abscission zone of mature 'Valencia' oranges [Citrus sinesis (L.) Osbeck] were determined by high-performance liquid chromatography and enzyme-linked immunosorbent assay from early November 1998 to mid-June 1999. Ethylene production of mature 'Valencia' oranges during the same period was determined by gas chromatography. IAA concentrations in the pulp and seed were three to five times lower than those in the peel over the 7-month observation period. IAA concentration in the abscission zone and peel was high from late April to mid-May, the period of less responsiveness to abscission chemicals. ABA concentration in the pulp was low over the entire observation period. ABA concentration in the abscission zone and peel was low during the less responsive period. Ethylene production was always low except for a slight increase during late December and early February. The IAA to $\mathrm{ABA}$ ratio was high in the fruit abscission zone during the less responsive period. Fruit detachment force of CMN-pyrazole-treated fruit was positively correlated with the ratio of endogenous IAA to ABA or endogenous IAA, but negatively to endogenous ABA in the fruit abscission zone. These data suggest the balance between IAA and ABA in the fruit abscission zone may be an important factor in determining sensitivity and thereby the response of mature 'Valencia' orange fruit to abscission chemicals. Chemical names used: abscisic acid (ABA); indole-3-acetic acid (IAA); 5-chloro-3-methyl-4-nitro-1 $\mathrm{H}$-pyrazole (CMN-pyrazole).
\end{abstract}

Most of the 'Valencia' oranges (Citrus sinesis) grown in Florida are used for processing and are harvested from early April through June (Wilson et al., 1981). Abscission chemicals can effectively reduce detachment force of mature 'Valencia' orange fruit and promote fruit abscission from mid-February through April. Then there is a period of 2 to 4 weeks during which the response of mature fruit to abscission chemicals is markedly reduced. Abscission chemicals become effective again after this period (Hartmond et al., 2000a; Holm and Wilson, 1976, 1977; Wheaton et al., 1977). However, little is known about the factors responsible for the less responsive period.

Oranges are nonclimacteric fruit and mature fruit abscise only at the abscission zone in the calyx (Brown, 1997; Goren, 1993). Endogenous plant hormones are involved in fruit abscission. The concentration of endogenous auxin in the abscission zone must decrease below a certain threshold to promote abscission (Osborne, 1989). In oranges, endogenous auxin and ethylene are two major hormones controlling the fruit or leaf abscission process (Goren, 1993). Application of 2,4 dichlorophenoxyacetic acid (2,4-D), a synthetic auxin, effectively reduced preharvest drop of orange fruit (Gardner et al., 1950; Zur and Goren, 1977). Sprays of abscisic acid (ABA) at $200 \mathrm{mg} \cdot \mathrm{L}^{-1}$ enhanced both ethylene production and fruit loosening of mature 'Valencia' oranges induced by the abscission chemical cycloheximide (CHI) (Cooper and Henry, 1972). Using explants of 'Pineapple' orange fruit and 'Valencia' orange fruit, Rasmussen (1974) found that ABA

Received for publication 5 Oct. 2000. Accepted for publication 9 Apr. 2001. Florida Agricultural Experiment Station journal series R-07801. We gratefully acknowledge financial support of the Florida Department of Citrus and assistance of Herbert N. Nigg and A. Grant. The cost of publishing this paper was defrayed in part by the payment of page charges. Under postal regulations, this paper therefore must be hereby marked advertisement solely to indicate this fact.

${ }^{1}$ Corresponding author; e-mail kender@lal.ufl.edu. introduced through the stem was more effective than spray application in promoting cellulase activity and reducing fruit detachment force. During the harvest season, new flushes, young fruit for the following year's crop, and roots grow rapidly. These young tissues are rich sources of endogenous plant hormones (Goldschmidt, 1976; Hofman, 1990; Plummer et al., 1991). Therefore, it has been speculated that endogenous plant hormones from these young tissues account for the reduced response of mature fruit to abscission chemicals in 'Valencia' oranges (Holm and Wilson, 1976; Rasmussen, 1973; Wheaton et al., 1977).

In a companion paper, we investigated seasonal variation in the response of mature 'Valencia' orange fruit to the abscission chemical CMN-pyrazole particularly with respect to the influence of young fruit, shoot, and root growth on this response (Yuan et al., 2001). The objective of the present study was to 1) determine the levels of endogenous plant hormones, especially indole-3-acetic acid (IAA), ABA, and ethylene from early November to mid June, and 2) evaluate the relationships between these endogenous hormones and the responsiveness of mature 'Valencia' orange fruit to the abscission chemical CMN-pyrazole.

\section{Materials and Methods}

Plant Materials. Nine uniform 10-year-old 'Valencia' orange trees grafted on rough lemon (Citrus jambhiri Lush) rootstock, were selected from a previously described grove located at the Citrus Research and Education Center, Lake Alfred, Fla. (Yuan et al., 2001), and separated into three replicate groups of three trees each. Fifteen fruit having pedicels 3 to $4 \mathrm{~cm}$ in length were collected from each tree at 1 - or 2 -week intervals beginning 12 Nov. 1998 and ending 15 June 1999. Forty-five fruit from each group at each sampling time were pooled and immediately 
separated into peel, pulp, seed, and abscission zone. The fruit abscission zones were removed according to the method of Kazokas and Burns (1998). Promptly after the separation of fruit, samples were frozen in liquid nitrogen, and lyophilized. All plant materials except the abscission zone were ground in a Wiley mill to pass a $40-$ mesh $(0.635-\mathrm{mm})$ screen, and used for measurement of free IAA and ABA. An additional 15 fruit were collected on each sampling date and used for determination of fruit ethylene production. Ten fruit from each replicate were also collected, washed, and used for measurement of fruit color.

EXTRACTION, PURIFICATION, AND MEASUREMENT OF FREE IAA AND ABA. The method of Bertling and Lovatt (1996) was modified to extract and partially purify plant materials for free IAA and ABA. Briefly, $3 \mathrm{~g}$ of ground peel, pulp, or seed, were placed in an Erlenmeyer flask. To each Erlenmeyer flask, $80 \mathrm{~mL}$ of $80 \%$ methanol containing butylated hydroxytoluene (BHT) at 40 $\mathrm{mg} \cdot \mathrm{L}^{-1}$ as an antioxidant was added, and the tissue was extracted overnight at $4^{\circ} \mathrm{C}$. The sample of abscission zone tissue was placed in a plastic centrifugation tube with 30 $\mathrm{mL}$ of $80 \%$ methanol containing BHT at $40 \mathrm{mg} \cdot \mathrm{L}^{-1}$, pulverized using a Brinkmann rotary homogenizer (Brinkmann Instruments Co., Westbury, N.Y.), transferred to an Erlenmeyer flask holding another $50 \mathrm{~mL}$ of $80 \%$ methanol containing BHT at $40 \mathrm{mg} \cdot \mathrm{L}^{-1}$, and then extracted overnight at $4{ }^{\circ} \mathrm{C}$. One hundred microliters of ${ }^{3} \mathrm{H}-\mathrm{IAA}(\approx 67 \mathrm{~Bq})$ and ${ }^{14} \mathrm{C}-\mathrm{ABA}(\approx 83 \mathrm{~Bq})$ were added as internal standards to the plant samples to determine the recovery rate. The crude extract was filtered through Whatman No. 2 filter paper and the residue was reextracted twice overnight at $4{ }^{\circ} \mathrm{C}$ in $80 \mathrm{~mL}$ of $80 \%$ methanol containing BHT at $40 \mathrm{mg} \cdot \mathrm{L}^{-1}$. The filtrates were combined and evaporated to the aqueous phase in vacuo at $35^{\circ} \mathrm{C}$. The aqueous phase was stored at $-20{ }^{\circ} \mathrm{C}$ overnight, thawed, and centrifuged at 15,000 $g_{\mathrm{n}}$ for $20 \mathrm{~min}$. The supernatant was adjusted to $\mathrm{pH} 8.0$ with $5 \% \mathrm{NH}_{4} \mathrm{OH}$ and loaded onto a column system that was first preconditioned and washed with $15 \mathrm{~mL}$ of $1.0 \mathrm{M}$ ammonium acetate $(\mathrm{pH} \mathrm{8.0)}$ and subsequently with $15 \mathrm{~mL}$ of $0.01 \mathrm{M}$ ammonium acetate ( $\mathrm{pH}$ 8.0). The column system consisted of an insoluble polyvinyl pyrrolidone $(\mathrm{PVP})(10 \times 1.5 \mathrm{~cm})$ and a diethylaminoethyl (DEAE) Sephadex anion exchange column $(10 \times 1.5 \mathrm{~cm})$. The column system was eluted with $0.01 \mathrm{~m}$ ammonium acetate $(\mathrm{pH} 8.0)$. A Sep-Pak $\mathrm{C}_{18}$ cartridge (Waters, Milford, Mass.) that was first preconditioned with $100 \%$ methanol and subsequently with $0.1 \mathrm{M}$ acetic acid was attached to the DEAE column of the column system. IAA and ABA were eluted with $1.5 \mathrm{M}$ acetic acid, and collected at the Sep-Pak $\mathrm{C}_{18}$ cartridge, which was rinsed with $10 \mathrm{~mL}$ of distilled water before IAA and ABA were eluted with $5 \mathrm{~mL}$ of $50 \%$ methanol. The eluates were dried in vacuo and dissolved in $2 \mathrm{~mL}$ of $100 \%$ high performance liquid chromatography (HPLC) grade methanol.

The samples were further purified by HPLC according to the method of Miller et al. (1987) with some modification. In brief, a $500 \mu \mathrm{L}$-sample containing IAA and ABA was applied to a $250 \times 4.6 \mathrm{~mm}$ Whatman Partisil ODS-3 $\mathrm{C}_{18}$ reverse phase column (5- $\mu \mathrm{m}$ particle size) at a flow rate of $1.0 \mathrm{~mL} \cdot \mathrm{min}^{-1}$ with a $15 \%$ to $80 \%(\mathrm{v} / \mathrm{v})$ gradient over a period of $50 \mathrm{~min}$ in a solution of $1 \%$ acetic acid, followed by an increase to $100 \%$ methanol over $5 \mathrm{~min}$. Fractions corresponding to IAA and ABA were collected and dried in vacuo.
ABA fractions were diluted with $25 \mathrm{~mm}$ Tris buffer ( $\mathrm{pH} 7.5$ ) before quantification by an enzyme-linked immunosorbent assay (ELISA). Tris buffer was prepared by diluting $3.03 \mathrm{~g}$ Trizma base, $5.84 \mathrm{~g} \mathrm{NaCl}, 0.2 \mathrm{~g} \mathrm{MgCl}_{2} \cdot 6 \mathrm{H}_{2} \mathrm{O}$, and $0.2 \mathrm{~g} \mathrm{NaN}_{3}$ in $1 \mathrm{~L}$ of distilled water and adjusted to $\mathrm{pH} 7.5$ with $\mathrm{HCl}$. IAA fractions were resuspended in $250 \mu \mathrm{L}$ of methanol, methylated with diazomethane, dried in vacuo, and redissolved in Tris buffer $(\mathrm{pH}$ 7.5) for assaying by ELISA. IAA and ABA were quantified by ELISA using monoclonal antibodies against IAA and ABA (Agdia Inc., Elkhart, Ind.) and the ELISA procedures were conducted as recommended by the manufacturer. The recovery rate was $\approx 70.2 \%$ for IAA, and $52.4 \%$ for ABA.

To determine the less-responsive period, groups of 20 uniform mature fruit were selected , marked, and sprayed with CMNPyrazole at $150 \mathrm{mg} \cdot \mathrm{L}^{-1}$ on each of four replicate trees on each date

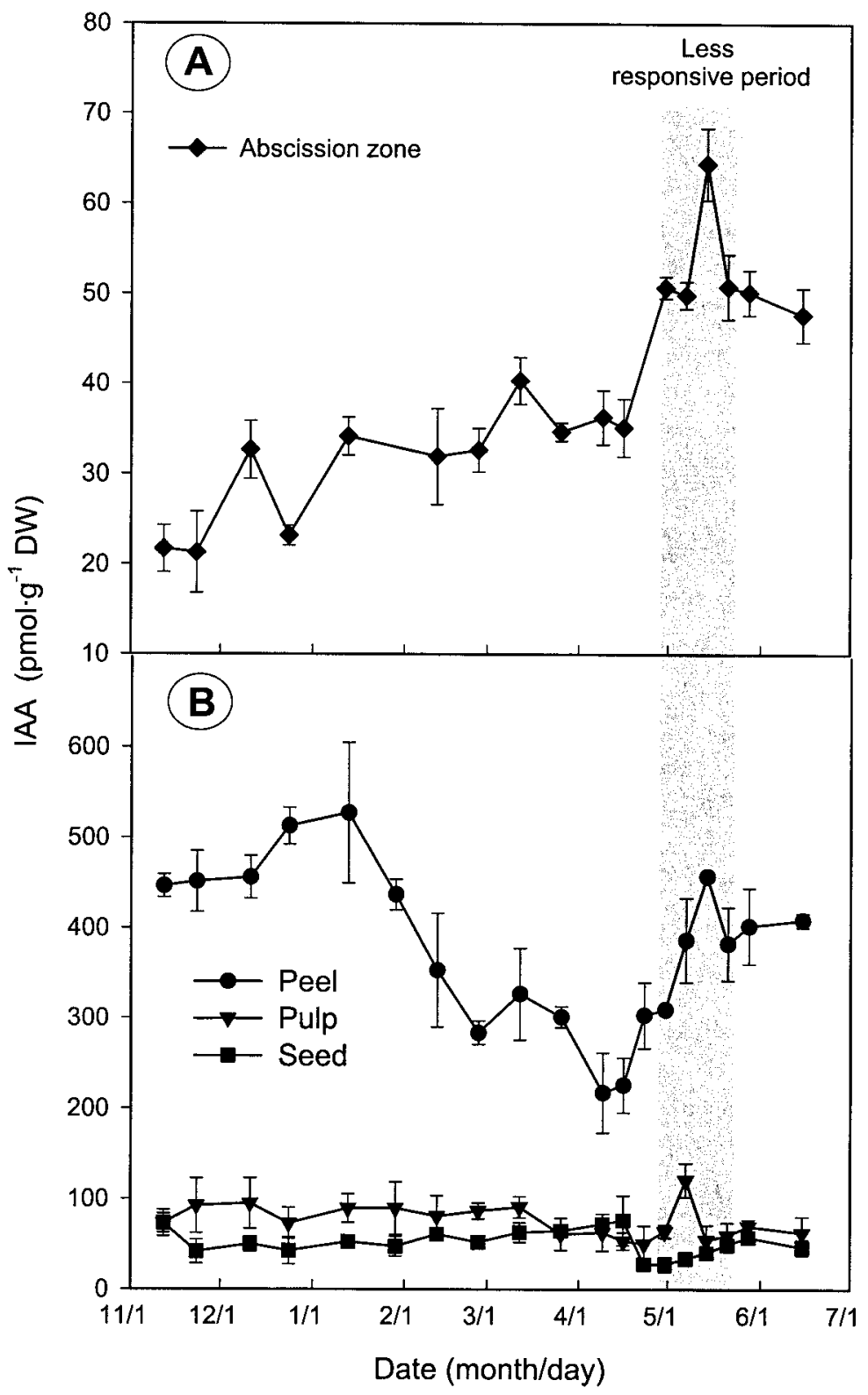

Fig. 1. Endogenous IAA concentrations in the (A) abscission zone and (B) peel, pulp, and seed of 'Valencia' orange fruit in the 1998-99 season. Data are means \pm SE $(n=3)$. 
at 7 to 10 d intervals from 9 Mar. 1999 to 2 June 1999 as reported in detail previously (Yuan et al., 2001). A total of 11 spray treatments were applied during the 3-month observation period. Fruit detachment force (FDF) was measured $7 \mathrm{~d}$ after each spray application using a digital force gauge (Force Five, Wagner Instruments, Greenwich, Conn.) (Hartmond et at., 2000a). The correlation between the endogenous hormone status (IAA, ABA, and their ratio) of nontreated mature fruit and the response in FDF of mature 'Valencia' orange fruit to the abscission chemical CMN-pyrazole were analyzed during 9 Mar. to 2 June 1999.

ETHYLENE MEASUREMENT. Ethylene concentration of mature 'Valencia' fruit was measured according to Hartmond et al. (2000b). Briefly, internal air was evacuated by vacuum from fruit submerged in degassed water and collected. Ethylene concentrations were measured with a gas chromatograph (Hewlett-Packard, Avondale, Pa.) equipped with an alumina column and flame ionization detector.

Fruit color measurement. On each sampling date, the peel color (chroma and hue angle) of 30 washed fruit was measured at three positions of each fruit around the equator using a chroma meter (CR200; Minolta Co., Asaka, Japan) measuring in CIE $1976\left(\mathrm{~L}^{*}, \mathrm{a}^{*}, \mathrm{~b}^{*}\right)$ (McGuire, 1992) [CIE = Commission Internationale de l'Eclairage (International Commission on Illumination)]. Chroma $\left(\mathrm{C}^{*}\right)$, calculated as $\left(\mathrm{a}^{* 2}+\mathrm{b}^{* 2}\right)^{1 / 2}$, is an index of color saturation or intensity (degree of departure from gray toward pure chromatic color $)$. Hue angle $\left(\mathrm{h}^{\circ}\right)\left(0^{\circ}=\right.$ red-purple, $90^{\circ}$

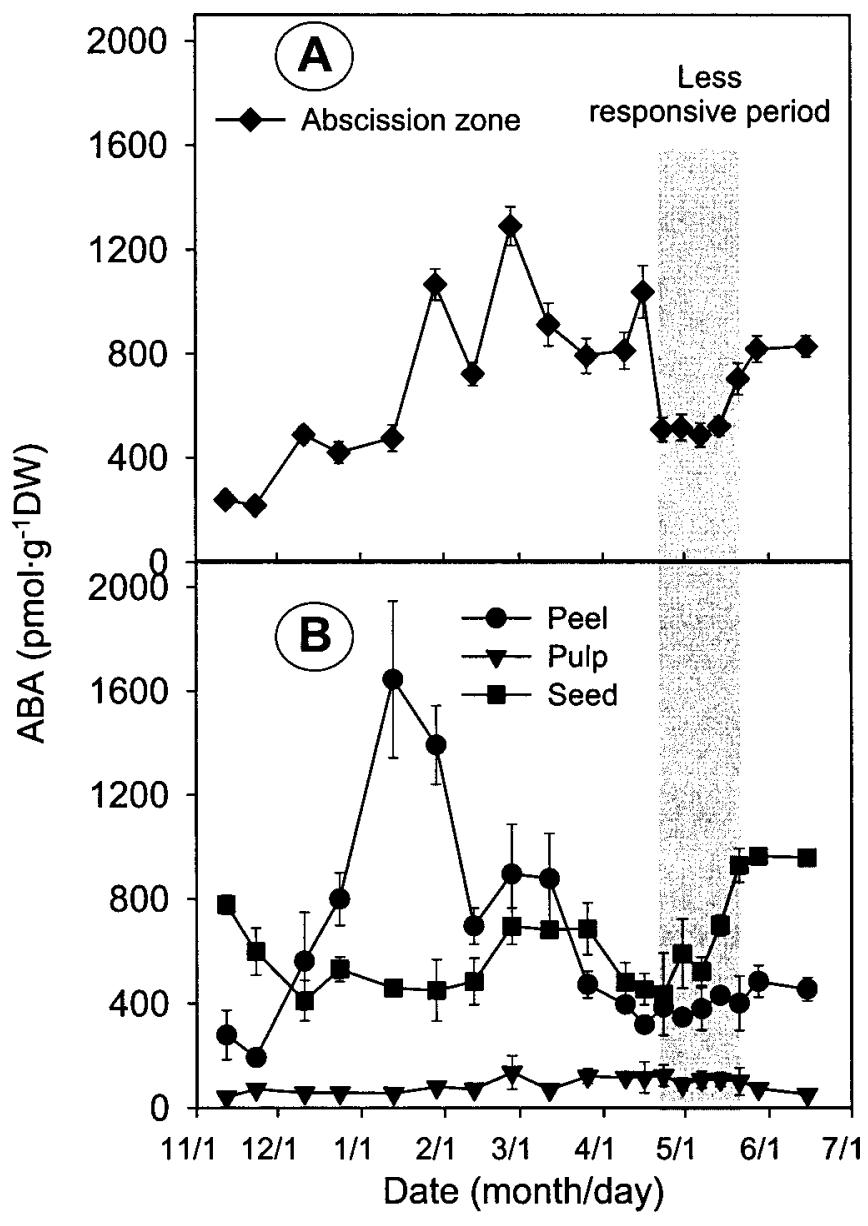

Fig. 2. Endogenous ABA concentrations in the (A) abscission zone and (B) peel, pulp, and seed of 'Valencia' orange fruit in the 1998-99 season. Data are means $\pm \operatorname{SE}(n=3)$.
$=$ yellow, $180^{\circ}=$ bluish green, and $270^{\circ}=$ blue) is calculated from the arctangent of $\mathrm{a} * / \mathrm{b} *$.

STATISTICAL ANALYSES. Statistical analyses included analysis of variance, Duncan's multiple range test, and regression analysis. Statistical Analysis Systems for PC (SAS Institute Inc., Cary, N.C.) was used for data analyses.

\section{Results}

Endogenous IAA concentrations in the abscission zone of 'Valencia' orange fruit were low, ranging from $\approx 20$ to $40 \mathrm{pmol} \cdot \mathrm{g}^{-1}$ dry weight (DW), from 12 Nov. 1998 to 16 Apr. 1999 (Fig. 1A). They increased dramatically in late April, reached a peak level of $\approx 70 \mathrm{pmol} \cdot \mathrm{g}^{-1} \mathrm{DW}$ on $14 \mathrm{May}$, and decreased thereafter. Overall, IAA concentration in the peel of fruit was markedly higher than that in the pulp, seed, and abscission zone over the more than 7 month observation period (Fig. 1A and B). IAA concentration in the peel was high ( $\left.\approx 500 \mathrm{pmol} \cdot \mathrm{g}^{-1} \mathrm{DW}\right)$ from $12 \mathrm{Nov} .1998$ to $13 \mathrm{Jan}$. 1999 , and decreased thereafter to a low level of $\approx 200 \mathrm{pmol} \cdot \mathrm{g}^{-1} \mathrm{DW}$ in early April. After 16 Apr. 1999, the IAA concentration increased and remained at a higher level $\left(\approx 400 \mathrm{pmol} \cdot \mathrm{g}^{-1} \mathrm{DW}\right)$ throughout the remainder of the sampling period. The period of less responsiveness of mature 'Valencia' orange fruit to CMN-pyrazole started late April and ended in late May (Yuan et al., 2001).

ABA concentration in the abscission zone of 'Valencia' orange fruit was low $\left(\approx 200 \mathrm{pmol} \cdot \mathrm{g}^{-1} \mathrm{DW}\right)$ in Nov. 1998 , increased thereafter, and remained at a relatively high level $(\approx 800$ to 1200 $\mathrm{pmol} \cdot \mathrm{g}^{-1} \mathrm{DW}$ ) from late January to mid-April 1999 (Fig. 2A). ABA concentration decreased rapidly to $\approx 420 \mathrm{pmol} \cdot \mathrm{g}^{-1} \mathrm{DW}$ by 23 Apr. 1999, and remained at a low level for 4 weeks followed by another abrupt increase. ABA concentration in the pulp was low over the entire observation period (Fig. 2B). The ABA concentration in the peel was low $\left(<400 \mathrm{pmol} \cdot \mathrm{g}^{-1} \mathrm{DW}\right)$ in Nov. 1998, and increased dramatically thereafter to a peak level of $1600 \mathrm{pmol} \cdot \mathrm{g}^{-1}$ DW in early January 1999 (Fig. 2B), followed by a steady decrease. After late March, ABA concentration in the peel was generally low $\left(\approx 400 \mathrm{pmol} \cdot \mathrm{g}^{-1} \mathrm{DW}\right.$ or less). The ABA concentration in the seed was low from late March to early May, and increased rapidly thereafter (Fig. 2B).

The ratio of IAA to ABA in the abscission zone of 'Valencia' orange fruit was high in November 1998, and then decreased gradually until late April 1999 (Fig. 3A). It increased $\approx 3$-fold after late April, and remained at a high level during the less responsive period. The ratio decreased again after late May when the less responsive period was over. The ratio of IAA to ABA in peel of mature 'Valencia' orange fruit was much higher than that in the abscission zone and showed a trend similar to that in the abscission zone, but less pronounced (Fig. 3B).

FDF of CMN-pyrazole-treated fruit was positively correlated with the ratio of endogenous IAA to ABA or endogenous IAA, but negatively correlated with endogenous ABA in the abscission zone (Fig. 4A, B, and C). There was no significant correlation between the FDF of CMN-pyrazole-treated fruit and endogenous IAA or ABA in the peel (Fig. 4E and F); however, there was a quadratic relationship between the ratio of endogenous IAA to ABA in peel and the FDF of CMN-pyrazole-treated fruit (Fig. 4D).

Overall, the ethylene concentration of nontreated 'Valencia' orange fruit was low during the observation period (Fig. 5). Fruit had slightly more ethylene during the period from late December 1998 to mid-February 1999 than at any other time of the observation period.

C* decreased quickly after early May, reflecting that fruit 


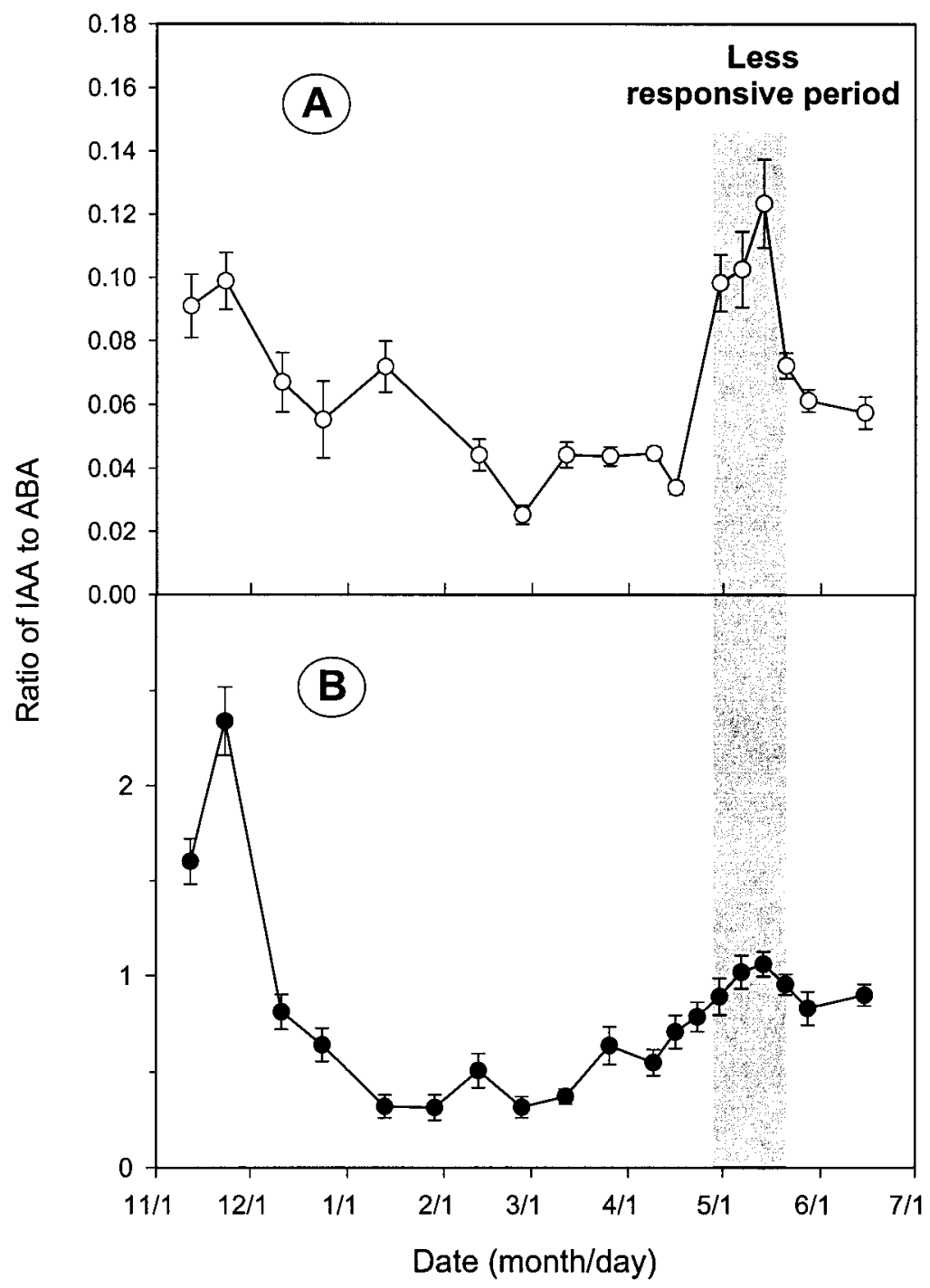

Burns, 1998). However, beginning in late April and lasting for $\approx 4$ weeks, there is a period of less responsiveness of mature 'Valencia' orange fruit to abscission chemicals (Cooper and Henry, 1972; Hartmond et al., 2000a; Wheaton et al., 1977; Yuan et al., 2001). In our study, the abscission zone had relatively high concentrations of endogenous IAA and low concentrations of endogenous ABA during the less responsive period. Detachment force of fruit treated with the abscission chemical, CMN-pyrazole, was positively associated with IAA, but negatively with ABA in the abscission zone. These results indicate that response of mature 'Valencia' orange to the abscission chemical CMNpyrazole is affected by the balance between IAA and ABA. Similarly, reduction in the endogenous IAA level and the increase of the endogenous ABA level in the abscission zone have been suggested to be responsible for water stress-induced young fruit abscission in cotton (Gossypium hirsutum L.) (Guinn and Brummett, 1988) and high temperature-induced abscission of pepper (Capsicum annиum L.) flowers and fruit (Huberman et al., 1997). In oranges, synthetic auxin was effectively used to prevent preharvest fruit drop (Goren, 1993; Zur and Goren, 1977). Our unpublished results showed that application of the synthetic auxin, naphthalene-1-acetic acid (NAA) to the abscission zone of mature 'Valencia' orange fruit $24 \mathrm{~h}$ before application of 2-chloroethylphosphonic acid (ethephon), an ethylene releasing compound, effectively inhibited reduction in FDF caused by ethephon. Application of the auxin transport inhibitor 2,3,5-triiodobenzoic acid (TIBA), however, increased responsiveness of mature 'Valencia' orange fruit to ethephon. Using bean (Phaseolus vulgaris L.) leaf explants, Tucker et al. (1988) reported that auxin, when applied $4 \mathrm{~h}$ before a $48 \mathrm{~h}$ treatment with ethylene, inhibited ethylene-induced expression of cellulase gene in the abscission zone, thereby reducing bean leaf abscission. In contrast, sprays of ABA at $200 \mathrm{mg} \cdot \mathrm{L}^{-1}$ to 'Valencia' orange fruit once a week beginning on 20

Fig. 3. IAA to ABA ratio in the (A) abscission zone and (B) peel of mature 'Valencia' orange fruit during the 1998-99 season. Data are means $\pm \operatorname{SE}(n=3)$.

color became less intense (Fig. 6A). Hue $^{\circ}$ were low in March and April, and increased rapidly after mid-May, indicating fruit were yellow orange until mid-May when regreening occurred (Fig. 6B).

\section{Discussion}

Fruit abscission, irrespective of maturity (young or mature), occurs at the abscission zone of the fruit. It is generally accepted that the balance between plant growth promoters and inhibitors are involved in fruit abscission (Addicott, 1982; Brown, 1997; Garcia-Papi and Garcia-Martinez, 1984; Goren, 1993; Guinn and Brummett, 1988). In oranges, it is well documented that abscission chemicals effectively reduce FDF and promote mature fruit abscission by stimulating ethylene production (Hartmond et al., 2000b; Holm and Wilson, 1976, 1977; Wheaton et al., 1977). This is followed by initiation of expression of genes of cellulase and polygalacturonase (Kazokas and Burns, 1998), de novo synthesis of hydrolytic enzymes in the abscission zone, degradation of the cell wall, and finally separation (Goren, 1993; Kazokas and
March and continuing through May, markedly enhanced fruit ethylene production and fruit loosening induced by the application of the abscission chemical CHI on 1 May (Cooper and Henry, 1972). It has been suggested that ABA when applied to Citrus leaf or fruit explants causes abscission by enhancing synthesis of 1aminocylopropane-1-carboxylic acid and thus promoting ethylene synthesis (Goren, 1993; Mehouachi et al., 2000). Leaf explants of navel oranges treated with Norflurazone, an inhibitor of $\mathrm{ABA}$ synthesis, contained less $\mathrm{ABA}$, produced less ethylene, and had lower ethylene sensitivity than the nontreated controls (Zacarias et al., 2000). Therefore, it is reasonable to assume that endogenous IAA and ABA in the fruit abscission zone are antagonistic in controlling responsiveness of 'Valencia' orange fruit to abscission chemicals. Poor response of 'Valencia' orange fruit to $\mathrm{CHI}$ in October and very early December reported by Cooper and Henry (1972) might also be due to the high ratio of IAA to ABA in the abscission zone that we measured during that period (Fig. 3A). Our recent unpublished results showed that the response of mature 'Valencia' orange fruit to $\mathrm{CMN}$-pyrazole was poor in October, November, and early December.

Fruit abscission usually has a closer relationship with the endogenous hormones in the abscission zone than in the fruit themselves. Heat stress induced abscission of reproductive or- 

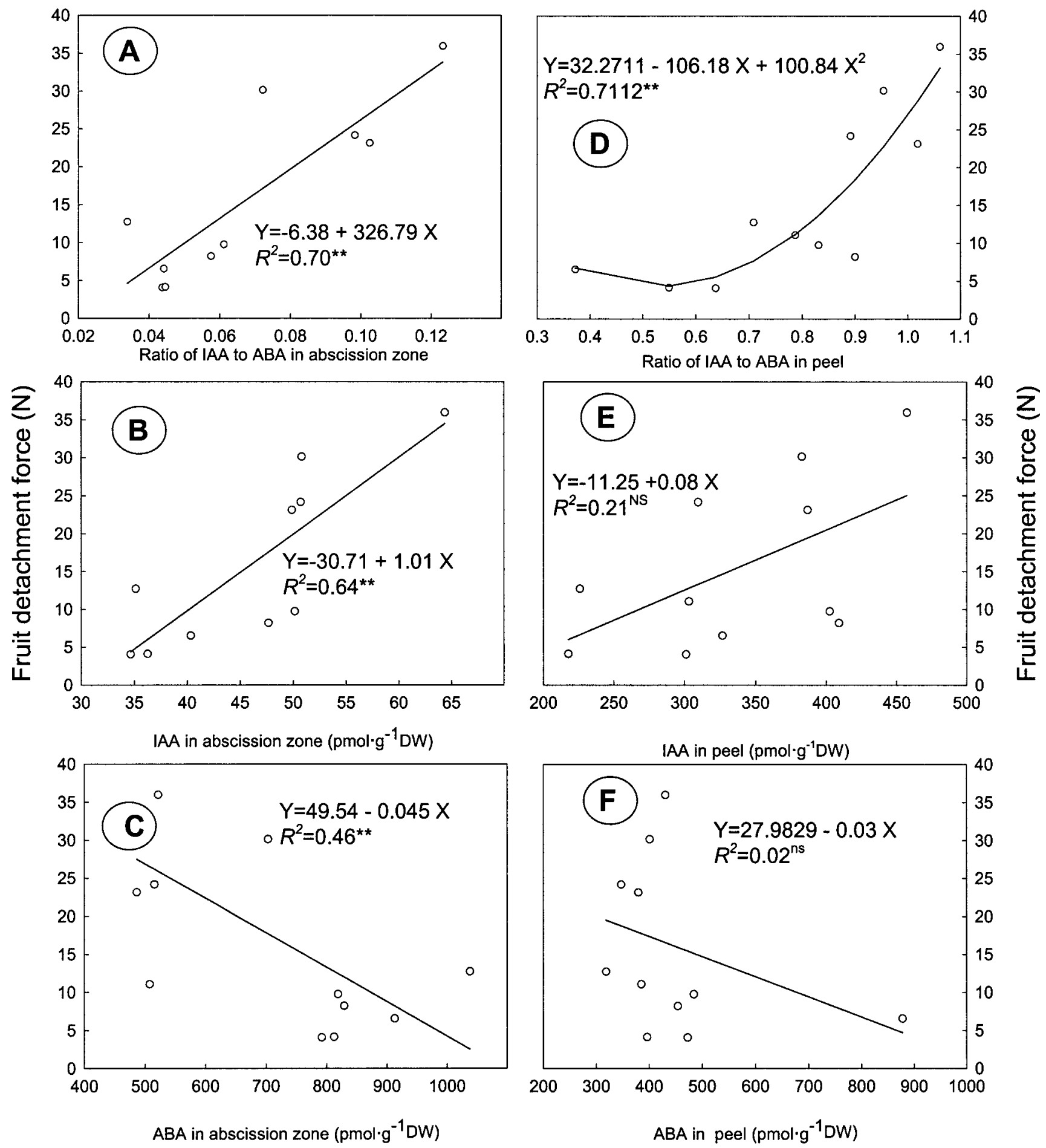

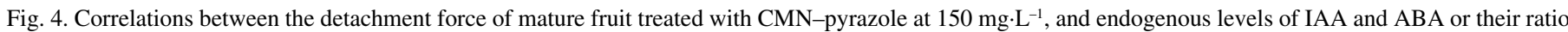

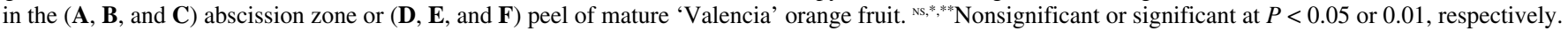

gans of bean (Ofir et al., 1993) or pepper (Huberman et al., 1997) was not closely related to changes of endogenous IAA levels in the reproductive organs, but closely related to changes in the abscission zone. In the present studies, response of mature 'Valencia' orange fruit to $\mathrm{CMN}$-pyrazole also had a less pronounced relationship with endogenous concentrations of IAA and $\mathrm{ABA}$ in the peel, which are the major sources of these hormones in Citrus (Monselise, 1977), than in the abscission zone. Similarly, Rasmussen (1974) reported that compared with introduction through the stem, spray application of ABA was less effective in inducing fruit abscission, since less ABA was translocated to the abscission zone. Abscission chemicals were also more efficient in promoting fruit abscission when they were applied directly to the abscission zone than to the fruit (Hartmond et al., 2000b). The ABA peak in the peel but not in the abscission zone measured in January was possibly the result of cold weather ( 5 to $10^{\circ} \mathrm{C}$ ). The source of the high IAA concentration in the abscission zone and the peel during the less responsive period has 
Fig. 5. Seasonal variation in ethylene concentration of 'Valencia' orange fruit in the 1998-99 season. Data are means \pm SE $(n=15)$.

not been established. Further experiments to determine effects of removal of young fruit alone or in combination with removal of spring vegetative shoots on changes of endogenous hormones in the abscission zone, peel, pulp, and seed of mature fruit during the less responsive period are being conducted to elucidate the sources of endogenous hormones.

Fruit ethylene production was low during the observation period except during the cool winter months (Fig. 5). Our results agreed with previous reports that Citrus fruit do not produce increased ethylene at maturation (Brown, 1997; Goren, 1993). The natural fruit ethylene concentration had no close relation with the less responsive period.

Results herein showed that fruit regreening occurred in mid- or late-May at the end of the less responsive period, which is consistent with previous reports that regreening of fruit rind and the less responsive period were not associated (Wheaton et al., 1977). It appears that endogenous IAA, ABA, or the ratio of endogenous IAA to ABA in the peel had no influence on fruit rind color.

In conclusion, our results suggest that the balance between IAA and ABA in the fruit abscission zone may be an important factor in determining sensitivity of mature 'Valencia' orange fruit to abscission chemicals, thereby controlling the response of mature 'Valencia' orange fruit to abscission chemicals. Endogenous IAA, ABA, or the ratio of endogenous IAA to $\mathrm{ABA}$ in the peel seem to be not associated with the regreening of fruit rind.

\section{Literature Cited}

Addicott, F.T. 1982. Abscission. Univ. California Press, Berkeley. Bertling, I. and C.J. Lovatt. 1996. A possible hormonal basis for vigor/dwarfing in commercially important citrus rootstocks. Proc. Intl. Soc. Citricult. 2:745-747.

Brown, K.M. 1997. Ethylene and abscission. Physiol. Plant. 100:567-576.

Cooper, W.C. and W.H. Henry. 1972. Effect of growth regulators on the response of citrus fruit to cycloheximide-induced abscission. Proc. Fla. State. Hort. Soc. 85:29-32.

Garcia-Papi, M.A. and J.L. Garcia-Martinez. 1984. Endogenous plant growth substances content in young fruits of seeded and seedless Clementine mandarin as related to fruit set and development. Scientia Hort. 22:265-274.

Gardner, F.E., P.C. Reece, and G.E. Horanic. 1950. The effect of 2,4-D on preharvest drop of citrus under Florida conditions. Proc. Fla. State. Hort. Soc. 63:7-11.

Goldschmidt, E.E. 1976. Endogenous growth substances of citrus tissue. HortScience 11:95-99.

Goren, R. 1993. Anatomical, physiological, and hormonal aspects of abscission in citrus. Hort. Rev. 15:145-182.

Guinn, G. and D.L. Brummett. 1988. Changes in free and conjugated indole-3-acetic acid and abscisic acid in young cotton fruits and their abscission zones in relation to fruit retention during and after moisture stress. Plant Physiol. 86:28-31.

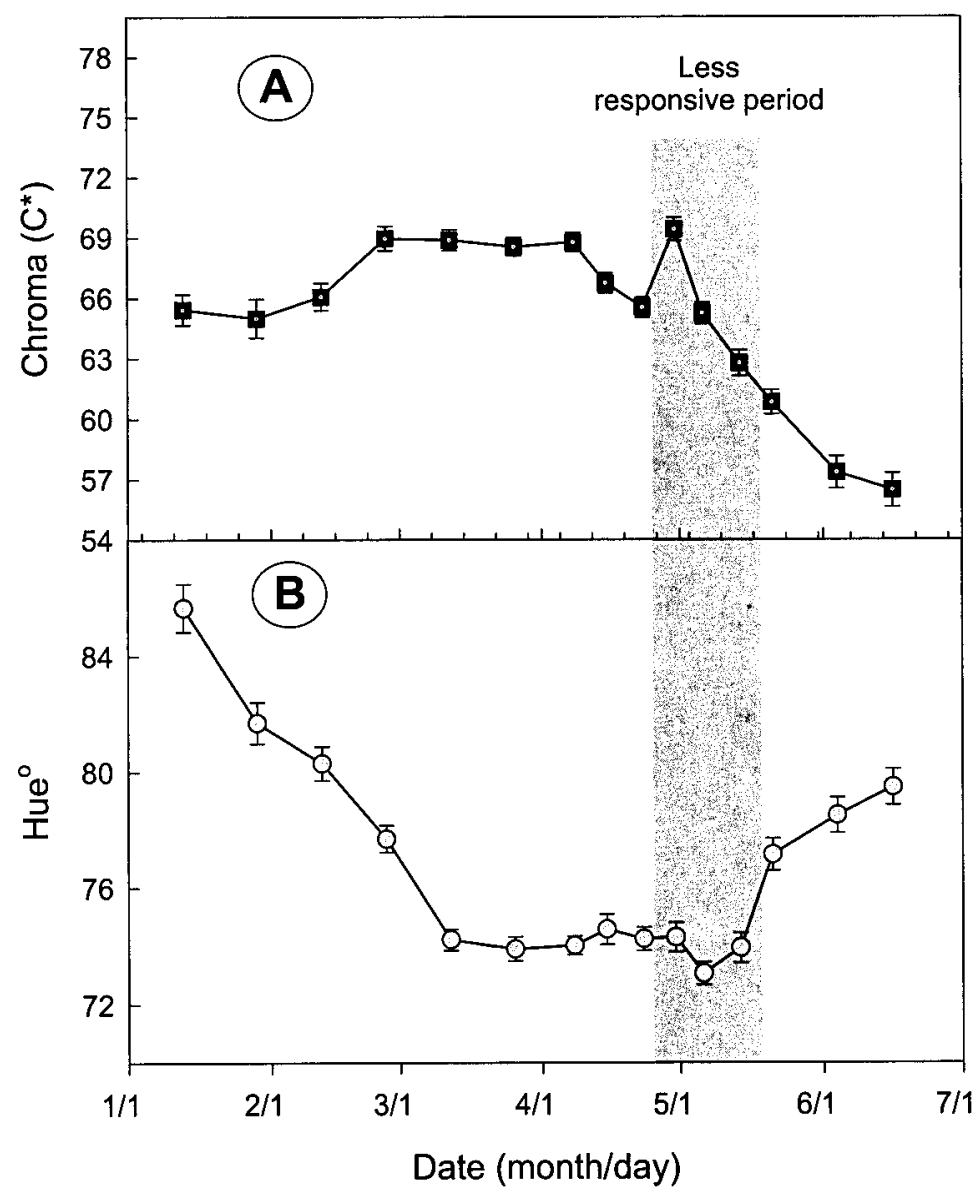

Fig. 6. Fruit rind color of mature 'Valencia' oranges in 1999. Data are means $\pm \mathrm{SE}$ $(\mathrm{n}=30) . \mathrm{C}^{*}=$ chroma (degree of departure from gray toward pure chromatic color $) \cdot \mathrm{h}^{\circ}=$ hue angle $\left(0^{\circ}=\right.$ red-purple, $90^{\circ}=$ yellow, $180^{\circ}=$ bluish green, and $270^{\circ}$ $=$ blue). 
Hartmond, U., J.D. Whitney, J.K. Burns, and W.J. Kender. 2000a. Seasonal variation in the response of 'Valencia' orange to two abscission compounds. HortScience 35:226-229.

Hartmond, U., R. Yuan, J.K. Burns, A. Grant, and W.J. Kender. 2000b. Citrus fruit abscission induced by methyl-jasmonate. J. Amer. Soc. Hort. Sci. 125:547-552.

Hofman, P.J. 1990. Abscisic acid and gibberellins in the fruitlets and leaves of 'Valencia' orange in relation to fruit growth and retention. Sci. Hort. 42:257-267.

Holm, R.E. and W.C. Wilson. 1976. Loss in the capacity of 'Valencia' oranges treated with abscission chemicals to produce ethylene and fruit loosening during the regreening period. Proc. Fla. State Hort. Soc. 89:35-38.

Holm, R.E. and W.C. Wilson. 1977. Ethylene and fruit loosening from combinations of citrus abscission chemicals. J. Amer. Soc. Hort. Sci. 102:576-579.

Huberman, M., J. Riov, B. Aloni, and R. Goren. 1997. Role of ethylene biosynthesis and auxin content and transport in high temperatureinduced abscission of pepper reproductive organs. J. Plant Growth Regulat. 16:129-135.

Kazokas, W.C. and J.K. Burns. 1998. Cellulase activity and gene expression in citrus fruit abscission zones during and after ethylene treatment. J. Amer. Soc. Hort. Sci. 123:781-786.

McGuire, R.G. 1992. Reporting of objective color measurements. HortScience 27:1254-1255.

Mehouachi, J., D.J. Iglesias, F.R. Tadeo, I. Lliso, J.L. Moya, A. GomezCadenas, E. Primo-Millo, and M. Talon. 2000. Citrus fruitlet abscission: Physiological bases supporting the "competition hypothesis". Proc. Intl. Soc. Citricult. (in press).

Miller, A.N., C.S. Walsh, and J.D. Cohen. 1987. Measurement of indole3 -acetic acid in peach fruits (Prunus persica L. Batsch cv. Redhaven) during development. Plant Physiol. 84:491-494.
Monselise, S.P. 1977. Citrus development: Endogenous systems and external regulation. Proc. Intl. Soc. Citricult. 2:664-668.

Ofir, M., Y. Gross, F. Bangerth, and J. Kigel. 1993. High temperature effects on pod and seed production as related to hormone levels and abscission of reproductive structures in common bean (Phaseolus vulgaris L.). Scientia Hort. 55:201-211.

Osborne, D.J. 1989. Abscission. Critical Rev. Plant Sci. 8:103-129.

Plummer, J.A., M.G. Mullins, and J.H. Vine. 1991. Seasonal changes in endogenous ABA and IAA and the influence of applied ABA and auxin in relation to shoot growth and abscission in Valencia orange [Citrus sinesis (L.) Osbeck]. Plant Growth Regulat. 10:139-151.

Rasmussen, G.K. 1973. The effect of growth regulators on degreening and regreening of citrus fruit. Acta Hort. 34:473-478.

Rasmussen, G.K. 1974. Cellulase activity in separation zones of citrus fruit treated with abscisic acid under normal and hypobaric atmospheres. J. Amer. Soc. Hort. Sci. 99:229-231.

Tucker, M.L., R. Sexton, E. del Campillo, and L.N. Lewis. 1988. Bean abscission cellulase. Plant Physiol. 88:1257-1262.

Wheaton, T.A., W.C. Wilson, and R.E. Holm. 1977. Abscission response and color changes of 'Valencia' oranges. J. Amer. Soc. Hort. Sci. 102:580-583.

Wilson, W.C., G.E. Coppock, and J.A. Attaway. 1981. Growth regulators facilitate harvesting of oranges. Proc. Intl. Soc. Citricult. 278-281.

Yuan, R., U. Hartmond, A. Grant and W.J. Kender. 2001. Physiological factors affecting response of mature 'Valencia' orange fruit to CMNPyrazole: I. Effects of young fruit, shoot, and root growth. J. Amer. Soc. Hort. Sci. 126(4):414-419.

Zacarias, L., F. Alferez, and A.D. Stead. 2000. Hormonal signals regulating the abscission process in citrus. Proc. Intl. Soc. Citricult. (in press).

Zur, A. and R. Goren. 1977. Reducing preharvest drop of 'Temple' orange fruits by 2,4-D. Role of cellulase in the calyx abscission zone. Scientia Hort. 7:237-248. 